\title{
Aspectos metodológicos do comportamento ingestivo de bovinos em pastejo
}

\author{
Jean Carlos Mezzalira ${ }^{1}$, Paulo César de Faccio Carvalho ${ }^{1}$, Lidiane Fonseca ${ }^{1}$, Carolina Bremm \\ Mônica Vizzotto Reffatti ${ }^{1}$, César Henrique Espírito Candal Poli ${ }^{1}$, Júlio Kuhn da Trindade ${ }^{1}$
}

1 Universidade Federal do Rio Grande do Sul - UFRGS, Avenida Bento Gonçalves 7712, 91501-970, Caixa Postal 776, Porto Alegre.

RESUMO - Avaliaram-se os tempos de pastejo de novilhas em pastagem natural, obtidos de forma visual em intervalos de 5 minutos. A partir dos dados originais, calcularam-se os intervalos de observação de 10, 15 e 20 minutos. Foram utilizadas quatro novilhas mestiças Angus $\times$ Nelore com peso médio de $249 \pm 6 \mathrm{~kg}$ PV. Empregou-se o delineamento de blocos casualizados com quatro tratamentos (ofertas de forragem de 4, 8, 12 e $16 \mathrm{~kg}$ de MS/100 kg de PV) e duas repetições, tendo como critério de bloqueamento o tipo de solo. O método de pastejo foi o contínuo com taxa de lotação variável. Os tempos de pastejo, ruminação e outras atividades não diferiram entre as escalas testadas, portanto, podem ser observados a cada 20 minutos, porém, o número e a duração das refeições e de seus intervalos apresentaram variações conforme a escala de observação. Somente a escala de observação de cinco minutos permitiu detectar as alterações diárias que compõem a dinâmica das refeições no comportamento ingestivo de animais em pastejo. Os cálculos comprovaram superestimação de 20 minutos na duração da refeição quando observada a cada 10 minutos em relação à observação a cada 5 minutos.

Palavras-chave: bioma Pampa, escalas de observação, oferta de forragem, pastagem natural

\section{Methodological aspects of ingestive behavior of grazing cattle}

\begin{abstract}
It was evaluated grazing times of heifers in natural pasture, obtained by visual assessment in 5-minute intervals. By using the original data, it was calculated observation intervals of 10, 15 and 20 minutes. It was used four crossbreed Angus $\times$ Nellore heifers, with average weight of $249 \pm 6 \mathrm{~kg}$ BW. The completely randomized block design was used with four treatments (forage allowance of 4, 8, 12 and $16 \mathrm{~kg} \mathrm{DM} / 100 \mathrm{~kg} \mathrm{BW}$ ) and two replicates, and type of soil was the blocking factor. The grazing method was continuous stocking with variable stocking rate. Grazing time, ruminating time and time of other activities did not differ among scales tested, therefore, they can be observed at every 20 minutes, but the number and duration of meals and its intervals presented variations according to observation scale. Only the observation scale of 5 minutes allowed the detection of daily modifications which compose meal dynamics upon the ingestive behavior of grazing animals. Estimates proved overestimation of 20 minutes in meal duration when observed at every 10 minutes in relation to the observation at every 5 minutes.
\end{abstract}

Key Words: bioma Pampa, forage allowance, natural pasture, observation scale

\section{Introdução}

Para entendimento das relações planta-animal, é imprescindível conhecer profundamente como plantas e animais se relacionam no processo de pastejo. Atualmente, a mudança do enfoque produtivista para a investigação dos processos envolvidos no ato do animal buscar seu alimento, via pastejo, assim como as consequências do pastoreio sobre o ambiente, tem assumido maior importância.

De acordo com Carvalho \& Moraes (2005), o animal transmite sinais, via comportamento ingestivo, sobre a abundância e qualidade de seu ambiente pastoril, que, se utilizado para ponderar ações de manejo, pode se tornar uma importante ferramenta de gestão do animal no pasto.

Para monitoramento do comportamento ingestivo, têm-se utilizado inúmeras técnicas/equipamentos, entre eles o colar Ethosys, GIS/GPS, Vibracorders, IGER Behavior Recorder, APEC, e mais recentemente gravadores do som emitido pelo animal em pastejo (bioacústica) (Carvalho et al., 2007). Entretanto, a observação visual permanece como a forma mais utilizada, por não demandar custo com equipamentos e, se realizada de forma correta, proporcionar boa descrição do comportamento ingestivo animal.

A literatura traz exemplos de protocolos com observações visuais em intervalos de cinco minutos 
(Salla et al., 2003; Mendonça et al., 2004; Mezzalira, 2009), sete minutos (Deswysen et al., 1993), dez minutos (Costa et al., 2003, Pinto et al., 2007; Baggio et al., 2008; Thurow et al., 2009), 15 minutos (Fischer et al., 1998; Portugal et al., 2000), até meia hora entre observações (Silva et al., 2004), porém os intervalos de dez minutos são os mais comuns na literatura.

A adoção do intervalo de tempo adequado é essencial para a confiabilidade dos resultados obtidos. A escolha desta escala, no entanto, em sua grande maioria, ocorre de forma arbitrária, sem considerar a complexidade do ambiente, o detalhamento que se pretende dar aos dados obtidos (Dutilleul, 1997) e quais respostas serão obtidas diante da confiabilidade desses resultados (Penning \& Rutter, 2004).

As variáveis e os tempos de pastejo, ruminação e outras atividades são os parâmetros mais comumente avaliados em estudos sobre o comportamento ingestivo. $\mathrm{O}$ clássico modelo conceitual de ingestão de forragem por animais em pastejo (Allden \& Whittaker, 1970) previa que o consumo diário seria o produto do tempo de pastejo e a taxa de ingestão. Mais recentemente, Rook (2000) aperfeiçoou esse conceito ao propor a distinção do tempo em pastejo a partir da duração das refeições e do número dessas refeições ao longo do dia.

Assim, este trabalho foi realizado com o objetivo de avaliar a precisão dos resultados obtidos entre intervalos de observações visuais de cinco minutos e os tempos obtidos por cálculo com intervalos de 10, 15 e 20 minutos nas avaliações de comportamento ingestivo de animais em pastejo com diferentes ofertas de forragem.

\section{Material e Métodos}

O experimento foi conduzido em uma pastagem natural da Estação Experimental Agronômica da UFRGS (RS-Brasil). O clima da região é do tipo $C f a$, subtropical úmido com verão quente (Tabela 1). Os tipos de solos predominantes são: Argissolo vermelho Distrófico típico ou arênico e Plintossolo (EMBRAPA, 1999). O período experimental foi de abril de 2007 a março de 2008 e as avaliações de comportamento realizadas nos dias 1/9/2007 (final de inverno) e 1/12/2007 (final de primavera). Os tratamentos consistiram de quatro ofertas de forragem: 4; 8; 12 e $16 \mathrm{~kg}$ de MS/100 kg de PV. O delineamento experimental foi o de blocos completamente casualizados com duas repetições de área, sendo que o fator de bloqueamento controlou a variação relacionada ao tipo de solo.

Os animais utilizados foram selecionados de um grupo de novilhas mestiças, oriundas de cruzamentos entre as raças Angus e Nelore, com idade e peso médio de 15 meses e $249 \pm 6 \mathrm{~kg}$, respectivamente. Desse grupo selecionaram-se os animais testers, tendo sido escolhido um lote homogêneo quanto ao peso, à condição corporal e ao temperamento. Após esta seleção, cada unidade experimental recebeu quatro animais testers, que foram divididos em grupos por tipo racial (por predominância) e posteriormente sorteados nas unidades experimentais.

A massa de forragem foi estimada visualmente com auxílio de um quadrado metálico de $0,25 \mathrm{~m}^{2}$, em 50 pontos amostrais por unidade experimental, amostrado exclusivamente o estrato pastejado do pasto. Esse estrato é composto, principalmente, por espécies de hábito de crescimento prostrado, como Paspalum notatum FI., Paspalum paucifolium Sw. e Axonopus affinis Chase. O estrato superior, por sua vez, abriga espécies eretas como Andropogon lateralis Ness, Aristida jubata (Arech.) Herter e Aristida laevis (Nees) Kunth, Eryngium horridum Malme e Erianthus spp., entre outras espécies de baixa preferência pelos animais (Boldrini, 1997).

A média dos 50 valores de massa de forragem estimados foi corrigida por uma equação de regressão estimada $\hat{y}=b_{0}$ $+\mathrm{b}_{1} \mathrm{x}$, gerada a partir de 54 locais amostrados em todo o experimento, segundo a técnica da dupla amostragem - método do rendimento comparativo (Haydock \& Shaw, 1975). Esses 54 pontos foram estimados visualmente e posteriormente cortados com tesoura elétrica, recolhidos em sacos de papel, secos em estufa de ar forçado a $60^{\circ} \mathrm{C}$ por 72 horas e pesados em balança de precisão.

A carga animal foi ajustada para a área efetivamente pastoril (obtida por meio da frequência de espécies não pastejadas) (Mezzalira, 2009), com intervalo médio de 28 dias. O método de pastejo foi o contínuo com taxa de lotação variável put-and-take (Mott \& Lucas, 1952). A taxa de acúmulo de forragem foi determinada pela técnica de gaiolas de exclusão ao pastejo (Klingman et al., 1943).

A oferta real de forragem foi calculada pelo quociente da média aritmética da massa de forragem inicial e final de cada subperíodo experimental pelo número de dias desse subperíodo mais a taxa de acúmulo correspondente. A disponibilidade foi dividida pela carga animal média do subperíodo, em kg/ha de PV, e o valor obtido multiplicado por 100 para expressar a oferta em porcentagem do peso vivo.

$\mathrm{ORF}=\{\{[(\mathrm{MFi}+\mathrm{MFf}) / 2] / \mathrm{n}+\mathrm{TA}\} / \mathrm{CA}\} * 100$, em que $\mathrm{MFi}=$ massa de forragem inicial e MFf = massa de forragem final do subperíodo (kg/ha de MS); n = número de dias do período; TA = taxa de acúmulo diário (kg/ha de MS); e $\mathrm{CA}=$ carga animal ( $\mathrm{kg} / \mathrm{ha}$ de PV).

O comportamento ingestivo foi determinado em intervalos de cinco minutos, do nascer ao pôr-do-sol, por 
dois observadores, por unidade experimental, previamente treinados, portando binóculos e posicionados em andaimes. Os dados, expressos em minutos, foram registrados como tempo de pastejo, tempo de ruminação e tempo de outras atividades, ao se observar e registrar instantaneamente as atividades dos quatro animais testers de cada unidade experimental. O tempo de pastejo foi considerada como o tempo gasto com as atividades de procura e colheita de forragem na pastagem, com o animal em atividade de ingestão.

O tempo de ruminação foi considerado como o período em que o animal não está pastejando, mas está mastigando o bolo alimentar retornado do rúmen, caracterizado por movimentos mandibulares cíclicos e repetitivos, onde o animal normalmente encontra-se parado. Por outras atividades entende-se o período em que o animal não está pastejando nem ruminando e inclui os períodos de descanso e em que o animal está bebendo água, ingerindo sal, etc.

Foi considerada como refeição uma sequência de pastejo interrompida por duas observações de não-pastejo, interrupção que caracteriza o que se denominou intervalo de refeições. A duração das refeições e do intervalo foi obtida pela soma dos intervalos de observação. Todas essas variáveis foram definidas conforme proposição de Gibb (1998).

Posteriormente, calcularam-se estas mesmas variáveis simulando observações a cada 10, 15 e 20 minutos, a partir das observações originais a cada cinco minutos, considerando a primeira observação do dia comum para todos os intervalos.

Os dados relacionados à pastagem, altura do pasto e massa de forragem, foram submetidos a análises de regressão até terceira ordem para cada avaliação, conforme o modelo: $\mathrm{Y}_{\mathrm{ij}}=\mathrm{a}+\mathrm{bx}_{\mathrm{ij}}+\mathrm{cx}_{\mathrm{ij}}{ }^{2}+\mathrm{dx}_{\mathrm{ij}}{ }^{3}+\varepsilon_{\mathrm{ij}}$, em que: $\mathrm{Y}_{\mathrm{ij}}=$ variável dependente; $\mathrm{a}=$ intercepto da regressão; $\mathrm{x}=$ variável independente; $\mathrm{b}$ = coeficiente linear de regressão da variável Y em relação à variável independente; c = coeficiente quadrático de regressão da variável Y relacionada à variável independente; $d$ = coeficiente cúbico de regressão da variável Y em relação à variável independente e $\varepsilon_{\mathrm{ij}}=$ erro aleatório residual.

Como a equação de regressão apresentou a mesma tendência nas duas avaliações, realizou-se a comparação das equações, pelos testes de paralelismo e de igualdade de interceptos. Constatado a igualdade entre elas $(\mathrm{P}>0,05)$, analisaram-se nova equação de regressão com o conjunto de dados de ambas as avaliações.

Os dados do comportamento ingestivo foram submetidos à análise de variância e comparação de médias pelo teste Tukey a 5\% de significância, ambas realizadas por meio do pacote estatístico SAS (2001).

\section{Resultados e Discussão}

A altura do pasto, nas duas avaliações, ajustou-se ao modelo linear de regressão de acordo com a oferta de forragem. Assim, a altura média dos pastos variou de 3,5 a $8,6 \mathrm{~cm}$ entre as ofertas de forragem de 4 e $16 \%$ (Figura 1). A massa de forragem, por sua vez, ajustou-se ao modelo quadrático em ambas as avaliações, demonstrando aumento até a oferta $14 \%$, a partir da qual ocorreu estabilização.

Os resultados comprovam o sucesso de se criar condições contrastantes de suficiência alimentar, de acordo com a proposição inicial do trabalho, que diferentes ofertas de forragem criam estruturas distintas no pasto. Isso ocorre porque ambientes pastoris criados a partir de ofertas de forragem contrastantes incorporam o efeito da qualidade do ambiente nos parâmetros de comportamento ingestivo.

De acordo com as observações do comportamento ingestivo, não houve diferença na duração dos períodos de pastejo $(\mathrm{P}=0,5706)$ e de ruminação $(\mathrm{P}=0,9695)$, tampouco interação entre os tratamentos de ofertas de forragem e as escalas de observação de 5, 10, 15 ou 20 minutos em nenhuma das duas avaliações (Tabela 2). A duração de outras atividades diferiu entre escalas de observação $(P=0,0024)$, apresentando interação com a oferta de forragem que os animais estavam submetidos.

Esses resultados estão de acordo com trabalhos apresentados por Carvalho et al. (2007a), que não observaram diferenças entre os mesmos intervalos de observação ao alimentar cabras lactantes em confinamento. Silva et al. (2008) não observaram diferenças nos tempos de pastejo e ruminação de vacas leiteiras entre intervalos de 10, 20 e 30 minutos. Da mesma forma, Salla et al. (1999) compararam registros de comportamento de vacas Jersey

Tabela 1 - Variáveis meteorológicas nas duas avaliações do comportamento ingestivo

\begin{tabular}{|c|c|c|c|c|c|c|}
\hline \multirow{2}{*}{\multicolumn{2}{|c|}{$\begin{array}{c}\text { Radiação solar global } \\
\text { calcm }^{2} / \text { dia** }^{* *}\end{array}$}} & \multicolumn{3}{|c|}{ Temperatura do ar $\left({ }^{\circ} \mathrm{C}\right)^{*}$} & \multirow{2}{*}{$\begin{array}{l}\text { Precipitação } \\
\text { mm }\end{array}$} & \multirow{2}{*}{$\begin{array}{l}\text { UR (psicrômetro } \\
\%\end{array}$} \\
\hline & & Média & Máxima & Mínima & & \\
\hline Avaliação 1 & 212 & 14,7 & 19,7 & 8,5 & 2,2 & 93 \\
\hline Avaliação 2 & 718 & 21,3 & 27,2 & 16,3 & 0,0 & 80 \\
\hline
\end{tabular}




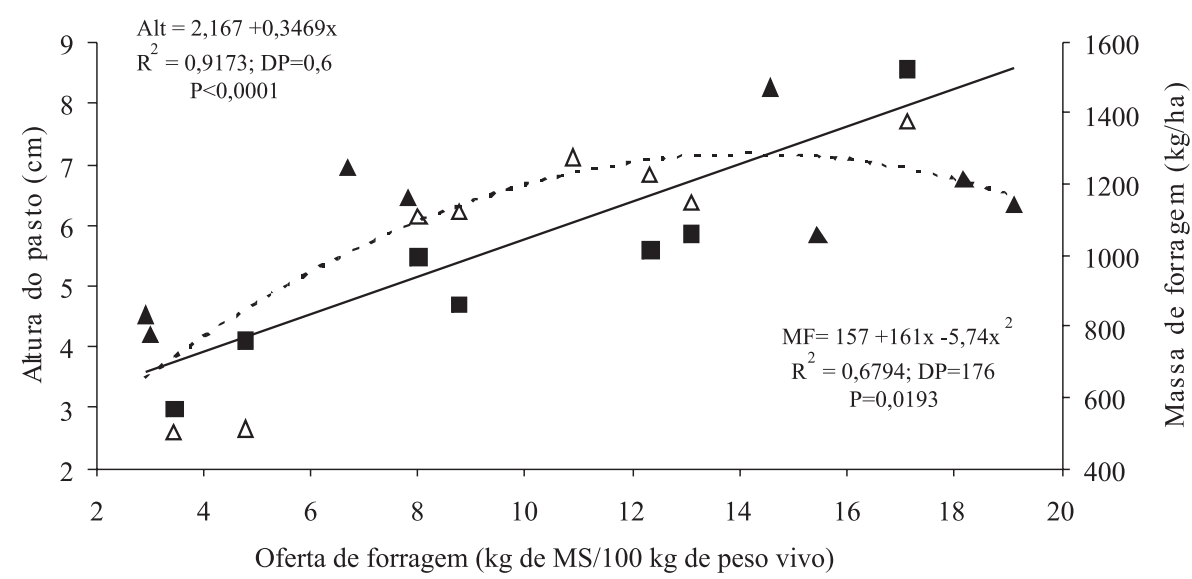

Equações de regressão geradas a partir de valores das duas avaliações:

$\Delta$ - MF no final do inverno; $\boldsymbol{\Delta}$ - MF no final da primavera; $\mathbf{a}$ - altura no final do inverno; $\square$ - altura no final da primavera); linha cheia - altura do pasto; linha pontilhada - massa de forragem

Figura 1 - Altura do pasto e massa de forragem em pastagem nativa manejada sob distintas ofertas de forragem.

Tabela 2 - Tempos de pastejo, ruminação e de outras atividades em pastagem nativa manejada em função de ofertas de forragem, conforme a épocas de avaliação

\begin{tabular}{|c|c|c|c|c|c|c|c|c|c|}
\hline & \multicolumn{5}{|c|}{ Intervalo entre observações } & \multirow[b]{2}{*}{$\operatorname{Min}^{\#}$} & \multirow[b]{2}{*}{ Per } & \multirow[b]{2}{*}{ Per*min } & \multirow[b]{2}{*}{$\mathrm{Min} * \mathrm{OF}$} \\
\hline & 5 & 10 & 15 & 20 & Média & & & & \\
\hline \multicolumn{10}{|c|}{ Tempo de pastejo } \\
\hline Inverno & 526 & 539 & 534 & 526 & $531 \mathrm{~B}$ & 0,5706 & $<0,0001$ & 0,6812 & 0,9919 \\
\hline Primavera & 631 & 626 & 637 & 619 & $628 \mathrm{~A}$ & & & & \\
\hline Média & 579 & 583 & 585 & 572 & & & & & \\
\hline \multicolumn{10}{|c|}{ Tempo de ruminação } \\
\hline Inverno & 90 & 91 & 86 & 92 & $90 \mathrm{~B}$ & 0,9695 & $<0,0001$ & 0,9361 & 0,9992 \\
\hline Primavera & 147 & 147 & 143 & 141 & $144 \mathrm{~A}$ & & & & \\
\hline Média & 118 & 119 & 114 & 117 & & & & & \\
\hline \multicolumn{10}{|c|}{ Tempo de outras atividades } \\
\hline Inverno & 112 & 108 & 118 & 111 & 112 & 0,0024 & 0,1153 & 0,4242 & 0,0603 \\
\hline Primavera & 92 & 100 & 96 & 117 & 101 & & & & \\
\hline Média & $102 b$ & $104 b$ & $107 b$ & $114 \mathrm{a}$ & & & & & \\
\hline
\end{tabular}

Valores seguidos de mesma letra diferem entre si pelo teste Tukey a 5\% (maiúscula na coluna e minúscula na linha).

Minn: significância entre escalas de observações.

Per: significância entre final de inverno e final de primavera.

lactantes e não notaram diferenças no tempo destas atividades.

Silva et al. (2004), avaliando o comportamento ingestivo de novilhas suplementadas em pastejo de Brachiaria decumbens, verificaram que os tempos de pastejo, ruminação e de outras atividades podem ser observados em uma escala de até 30 minutos. Silva et al. (2008), trabalhando com vacas mestiças Holandês $\times$ Zebu, não observaram diferenças no tempo de pastejo entre observações a cada 10 ou 30 minutos.

Por conseguinte, e de acordo com esses resultados, a escala de 20 minutos pode ser utilizada para descrever as atividades de pastejo e de ruminação, e a escala de dez minutos é suficiente para descrever outras atividades. Mesmo havendo interações entre intervalo de observações e período do ano, ficou evidente que qualquer diferença conduz à obrigatoriedade da observação em intervalo menor possível.

A duração de refeições (Tabela 3) foi fortemente influenciada pelo intervalo entre observações ( $\mathrm{P}<0,0001)$, não ocorrendo interação entre os tratamentos e os intervalos entre observações $(\mathrm{P}>0,05)$. O maior intervalo de observações superestimou a duração do período que o animal permaneceu em pastejo. Silva et al. (2008), comparando as escalas de 10, 20 e 30 minutos, constataram que a escala de 10 minutos descreve melhor o comportamento discreto dos animais em pastejo em comparação às demais escalas testadas. Entretanto, escalas de observação superiores a cinco minutos não descrevem fielmente a distribuição das refeições e de seus intervalos. 
Tabela 3 - Duração, número e intervalos entre refeições de novilhas de corte em pastagem nativa manejada em função de ofertas de forragem, conforme a épocas de observação

\begin{tabular}{|c|c|c|c|c|c|c|c|c|c|}
\hline & \multicolumn{5}{|c|}{ Intervalo entre observações } & \multirow[b]{2}{*}{$\operatorname{Min}^{\#}$} & \multirow[b]{2}{*}{ Per } & \multirow[b]{2}{*}{ Per*min } & \multirow[b]{2}{*}{$\operatorname{Min} * O F$} \\
\hline & 5 & 10 & 15 & 20 & Média & & & & \\
\hline \multicolumn{10}{|c|}{ Duração de refeições } \\
\hline Inverno & 142 & 158 & 191 & 235 & 182B & $<0,0001$ & 0,0307 & 0,2311 & 0,4988 \\
\hline Primavera & 175 & 178 & 208 & 228 & $197 \mathrm{~A}$ & & & & \\
\hline Média & $159 c$ & $168 c$ & 199b & $232 \mathrm{a}$ & & & & & \\
\hline \multicolumn{10}{|c|}{ Número de refeições } \\
\hline Inverno & $3,8 \mathrm{a}$ & $3,7 \mathrm{a}$ & $3,1 b$ & $2,6 b$ & $3,3 \mathrm{~A}$ & $<0,0001$ & 0,0008 & $<0,0001$ & 0,5198 \\
\hline Primavera & $2,0 \mathrm{c}$ & $3,7 \mathrm{a}$ & $3,3 b$ & $3,0 \mathrm{~b}$ & $3,0 \mathrm{~B}$ & & & & \\
\hline Média & 2,9 & 3,7 & 3,2 & 2,8 & & & & & \\
\hline \multicolumn{10}{|c|}{ Número de intervalos } \\
\hline Inverno & 3,6a & $3,4 \mathrm{a}$ & $2,7 b$ & $2,3 c$ & $3,0 \mathrm{~A}$ & $<0,0001$ & $<0,0001$ & $<0,0001$ & 0,2726 \\
\hline Primavera & $1,8 \mathrm{c}$ & 3,3a & $2,7 b$ & $2,5 b$ & $2,6 \mathrm{~B}$ & & & & \\
\hline Média & 2,7 & 3,4 & 2,7 & 2,4 & & & & & \\
\hline \multicolumn{10}{|c|}{ Duração de intervalos } \\
\hline Inverno & 51 & 58 & 75 & 83 & $67 \mathrm{~B}$ & $<0,0001$ & 0,0007 & 0,9283 & 0,0431 \\
\hline Primavera & 71 & 83 & 92 & 100 & $86 \mathrm{~A}$ & & & & \\
\hline Média & $61 \mathrm{~d}$ & $71 \mathrm{c}$ & $84 \mathrm{~b}$ & $91 \mathrm{a}$ & & & & & \\
\hline
\end{tabular}

Valores seguidos de mesma letra, na linha, não diferem entre si pelo teste Tukey a 5\%.

Min*: significância entre escalas de observações.

Per*min: interação entre período e minuto.

Min*OF: interação entre escala de observação e oferta de forragem.

Silva et al. (2005) observaram que intervalos de observações superiores a cinco minutos podem levar a perda de precisão na observação visual, comprometendo, portanto, a acurácia da avaliação dessas variáveis. Não obstante, Silva et al. (2008) não observaram diferença no número de refeições entre as escalas de 10 e 20 minutos.

O número de refeições e de intervalos foi influenciado pelos intervalos de observação, e isso comprova que somente na escala de cinco minutos entre as observações tem-se a acurácia necessária. Carvalho et al. (2007b) observaram que a escala de cinco minutos é a mais recomendada por permitir detectar, detalhadamente, a distribuição do pastejo ao longo do dia.

Mezzalira (2009) trabalhou com pastagem nativa e novilhas de corte aplicando intervalos de observação de cinco minutos e observou que a duração de refeições de animais sob oferta de forragem de $4 \%$ é 63 minutos maior que a observada em animais sob oferta de forragem de $16 \%$, fato que permitiu identificar essas diferenças comportamentais, que não seriam detectadas em uma escala de observação de 20 minutos. De acordo com esse autor, com 73 minutos a mais na duração da refeição com uso da escala de 20 minutos, pode-se fazer uma falsa inferência sobre o estado nutricional do animal, dizendo que este se encontra sob uma oferta de 8,5\%, enquanto está sendo mantido, realmente, a uma oferta igual a 3,1\%. O mesmo ocorreu quando se aplicou a escala de dez minutos, mas, neste caso, a superestimação na duração da refeição foi menor (20 minutos).
Segundo Carvalho et al. (2005), a duração da refeição está diretamente relacionada à velocidade de ingestão de matéria seca. Um animal em maior oferta de forragem, em pastos altos, obtém alta taxa de ingestão e isso reflete na mais rápida saciedade (menor duração de refeição) e maior tempo de saciedade (maior duração de intervalos). Ressaltando, ainda mais, a importância de se utilizar uma escala de 5 minutos, evitando confusões nas inferências do estado nutricional do animal. Independentemente da oferta de forragem à que o animal está submetido.

Independentemente da oferta de forragem houve aumento $(P=0,0431)$ da duração do intervalo calculado para escalas maiores que 5 minutos. De modo geral, escalas maiores de observação superestimaram o período de intervalo entre refeições (Tabela 4).

Tabela 4 - Duração dos intervalos entre refeições de novilhas em uma pastagem nativa manejada com quatro ofertas de forragem em duas épocas de observação

\begin{tabular}{lccccc}
\hline & \multicolumn{5}{c}{$\begin{array}{c}\text { Intervalo de observações } \\
\text { (minutos) }\end{array}$} \\
\cline { 2 - 5 } & 5 & 10 & 15 & 20 & Média \\
\hline $4 \%(\mathrm{~kg}$ de MS/100 kg PV) & $68 \mathrm{~b}$ & $76 \mathrm{~b}$ & $100 \mathrm{a}$ & $81 \mathrm{~b}$ & 81 \\
$8 \%(\mathrm{~kg}$ de MS/100 kg PV) & $63 \mathrm{~b}$ & $66 \mathrm{~b}$ & $81 \mathrm{a}$ & $86 \mathrm{a}$ & 74 \\
$12 \%(\mathrm{~kg}$ de MS/100 kg PV) & $52 \mathrm{c}$ & $75 \mathrm{~b}$ & $73 \mathrm{~b}$ & $104 \mathrm{a}$ & 76 \\
$16 \%(\mathrm{~kg}$ de MS/100 kg PV) & $62 \mathrm{~b}$ & $65 \mathrm{~b}$ & $81 \mathrm{a}$ & $93 \mathrm{a}$ & 75 \\
Média & 51 & 58 & 75 & 82 & \\
\hline
\end{tabular}

Valores seguidos de mesma letra na linha ou coluna não diferem entre si pelo teste Tukey a $5 \%$. 
Constatou-se diferença na duração máxima da refeição ( $P=0,0152)$ e na duração mínima da refeição, que apresentaram interação entre escala de observação e período experimental $(\mathrm{P}=0,0269)$. O intervalo mínimo entre refeições foi afetado pela escala de observação $(\mathrm{P}<0,0001)$, sendo superestimado com o aumento do intervalo entre observações (Tabela 5). Não foi observada diferença na duração máxima dos intervalos ( $\mathrm{P}=0$,2607).

Assim como na duração média de refeições e intervalos, os valores de duração mínimos e máximos foram superestimados com o aumento do intervalo entre observações visuais. Entretanto, maiores efeitos são observados nos períodos mais discretos, onde a duração mínima de refeições é aumentada em 25 e 12\%, nas duas avaliações, respectivamente ao se passar da escala de cinco para dez minutos (Tabela 5).

Desse modo, o uso do comportamento ingestivo de ruminantes em pastejo somente cumpre sua essência quando descreve de forma minuciosa e detalhada as atividades desenvolvidas pelos animais em pastejo. Somente assim, por meio do comportamento, é possível fazer inferências sobre a condição da vegetação e utilizar a observação dos animais como uma ferramenta de manejo (Carvalho \& Moraes, 2005).
De acordo com os resultados observados em intervalos maiores, como em 10 ou 20 minutos, pode-se concluir erroneamente que animais estão em boas condições alimentares, o que não é necessariamente verdadeiro. Essa conclusão se deve unicamente à má escolha da escala de observação.

Somente com a escala de observação de cinco minutos é possível detectar pequenas alterações diárias no comportamento dos animais, diminuindo, assim, erros de observação principalmente relacionados a atividades de refeição.

A publicação de resultados de comportamento ingestivo tem atingido níveis de usuais, com trabalhos onde não se notam compromissos com modelos conceituais, tampouco com testes de hipóteses específicas. Dada a "facilidade de obtenção" dos parâmetros comportamentais via observação visual, os dados de comportamento ingestivo tem sido publicados como "resultados adicionais" de protocolos que têm em sua origem outros objetivos. Carvalho et al. (2007c) alertaram quanto aos riscos dessa banalização, pois variáveis, como os tempos em atividades em pastejo e ruminação, têm sido utilizadas de forma desvinculada de qualquer modelo preditivo, sem investigação adequada das relações de causa-efeito

Tabela 5 - Duração de refeições e de intervalos máximos e mínimos de uma pastagem nativa manejada em função de ofertas de forragem em duas épocas de observação

\begin{tabular}{|c|c|c|c|c|c|c|c|c|c|}
\hline & \multicolumn{5}{|c|}{ Intervalo entre observações (min) } & \multirow[b]{2}{*}{$\operatorname{Min}^{\#}$} & \multirow[b]{2}{*}{ Per*min } & \multirow[b]{2}{*}{ Min*Per } & \multirow[b]{2}{*}{$\mathrm{Min}^{*} \mathrm{OF}$} \\
\hline & 5 & 10 & 15 & 20 & Média & & & & \\
\hline \multicolumn{10}{|c|}{ Duração máxima de refeições } \\
\hline Inverno & 243 & 260 & 278 & 303 & 271 & 0,0152 & 0,6587 & 0,6587 & 0,3211 \\
\hline Primavera & 264 & 265 & 273 & 296 & 275 & & & & \\
\hline Média & $254 b$ & $262 b$ & $276 b$ & $299 a$ & & & & & \\
\hline \multicolumn{10}{|c|}{ Duração mínima de refeições } \\
\hline Inverno & $52 c$ & $65 c$ & $114 \mathrm{~b}$ & $172 \mathrm{a}$ & 101 & $<0,0001$ & 0,0269 & 0,0082 & 0,5192 \\
\hline Primavera & $92 b$ & $103 b$ & $142 \mathrm{a}$ & $145 \mathrm{a}$ & 120 & & & & \\
\hline Média & 72 & 84 & 128 & 159 & & & & & \\
\hline \multicolumn{10}{|c|}{ Duração mínima de intervalos entre refeições } \\
\hline Inverno & 21 & 29 & 47 & 47 & 36 & $<0,0001$ & 0,7725 & 0,6137 & 0,0541 \\
\hline Primavera & 40 & 39 & 55 & 56 & 48 & & & & \\
\hline Média & $30 \mathrm{~b}$ & $34 b$ & $51 \mathrm{a}$ & $51 \mathrm{a}$ & & & & & \\
\hline
\end{tabular}

envolvidas. Essas relações têm sido usadas somente como "variáveis emergentes" e tratadas como informações meramente adicionais nas publicações científicas, particularmente as nacionais (Carvalho et al., 2007c).

\section{Conclusões}

Quando o objetivo da avaliação de comportamento ingestivo é descrever atividades de pastejo, ruminação e 
outras atividades, observações a cada 20 minutos são suficientes. Entretanto, quando a partir dessas atividades se pretende calcular outras, como aquelas relacionadas à dinâmica das refeições, são necessárias observações a cada 5 minutos. Para que o comportamento ingestivo possa ser usado como ferramenta de descrição da condição da pastagem e da boa alimentação dos animais, podendo conduzir a ações de manejo, recomenda-se que as observações sejam realizadas a cada 5 minutos.

\section{Referências}

ALLDEN, W.G.; WHITTAKER, A.M. The determinants of herbage intake by grazing sheep: the interrelationship of factors influencing herbage intake and availability. Australian Journal Agricultural Research, v.21, p.755, 1970.

BAGGIO, C.; CARVALHO, C.F.C.; SILVA, J.L.S. et al. Padrões de uso do tempo por novilhos em pastagem consorciada de azevém anual e aveia-preta. Revista Brasileira de Zootecnia, v.37, n.11, p.1912-1918, 2008.

BOLDRINI, I.I. Campos do Rio Grande do Sul: Caracterização fisionômica e problemática ocupacional. Boletim do Instituto de Biociências, 1997. p.1-39.

CARVALHO, G.G.P.; PIRES, A.J.V.; SILVA, H.G.O. et al. Aspectos metodológicos do comportamento ingestivo de cabras lactantes alimentadas com farelo de cacau e torta de dendê. Revista Brasileira de Zootecnia, v.36, n.1, p.103-110, 2007 a.

CARVALHO, G.G.P.; PIRES, A.J.V.; SILVA, R.R. et al. Aspectos metodológicos do comportamento ingestivo de ovinos alimentados com capim-elefante amonizado e subprodutos agroindustriais. Revista Brasileira de Zootecnia, v.36, n.4, p.1105-1112, 2007b (supl.)

CARVALHO, P.C.F.; KOZLOSKI, G.V.; RIBEIRO FILHO, H.M.N. et al. Avanços metodológicos na determinação do consumo de ruminantes em pastejo. Revista Brasileira de Zootecnia, v.36, p.151-170, 2007c (supl. especial).

CARVALHO, P.C.F.; MORAES, A. Comportamento ingestivo de ruminantes: bases para o manejo sustentável do pasto. In: MANEJO SUSTENTÁVEL EM PASTAGEM, 1., 2005, Maringá. Anais... Maringá: UEM, 2005. p.1-20.

CARVALHO, P.C.F. O manejo da pastagem como gerador de ambientes pastoris adequados à produção animal. In: PEDREIRA, C.G.S. et al. (Eds.). Teoria e prática da produção animal em pastagens. Anais... Piracicaba, 2005. p.7-32.

COSTA, C.O.; FISCHER, V.; VETROMILLA, M.A.M. et al. Comportamento ingestivo de vacas Jersey confinadas durante a fase inicial da lactação. Revista Brasileira de Zootecnia, v.32, n.2, p.418-424, 2003.

DESWYSEN, A.G.; DUTILlEUl, P.A.; GODFRIN, J.P. Nycterohemeral eating and ruminanting patterns in heifers fed grass or corn silage: analysis by finite fourier transform. Journal of Animal Science, v.71, n.10, p.2739-2747, 1993.

DUTILLEUL, P. Incorporating scale in study design: data analysis. In: PETERSON, D.L.; PARKER, V.T. (Eds.). Ecological Scale: theory and application. New York: Columbia University Press, 1997. p.1-77.

EMPRESA BRASILEIRA DE AGROPECUÁRIA - EMBRAPA. Centro Nacional de Pesquisa do Solo - CNPS. Sistema Brasileiro de Classificação de Solos. Rio de Janeiro: EMBRAPA, 1999. 412p.

FISCHER, V.; DESWYSEN, A.G.; DÈSPRES, L. et al. Padrões nictemerais do comportamento ingestivo de ovinos. Revista Brasileira de Zootecnia, v.27, n.2, p.362-369, 1998.
GIBB, M. Animal grazing/intake terminology and definitions. In: PASTURE ECOLOGY AND ANIMAL INTAKE, 3., 1996, Dublin. Proceedings... Dublin, 1998. p.21-37.

HAYDOCK, K.P.; SHAW, N.H. The comparative yield method for estimating dry matter yield of pasture. Australian Journal of Agricultural and Animal Husbandry, v.15, p.66-70, 1975.

KLINGMAN, D.L; MILES, S.R.; MOTT, G.O. The cage method for determining consumption and yield of pasture herbage. Journal of the Animal Society of Agronomy, v.35, p.739$746,1943$.

MENDONÇA, S.S.; CAMPOS, J.M.S.; VALADARES FILHO, S.C. et al. Comportamento ingestivo de vacas leiteiras alimentadas com dietas à base de cana-de-açúcar ou silagem de milho. Revista Brasileira de Zootecnia, v.33, n.3, p.723-728, 2004.

MEZZALIRA, J.C. O manejo do pastejo em ambientes pastoris heterogêneos: comportamento ingestivo e produção animal em distintas ofertas de forragem. 2009. 159f. Dissertação (Mestrado em Zootecnia) - Faculdade de Agronomia/ Universidade Federal do Rio Grande do Sul, Porto Alegre.

MOTT, G.O.; LUCAS, H.L. The design, conduct, and interpretation of grazing trials on cultivated and improve pastures. In: INTERNATIONAL GRASSLAND CONGRESS, 6., 1952, Pensylvania. Proceedings... Pensylvania, 1952. p.1380-1385.

PENNING, P.D.; RUTTER, S.M. Ingestive behaviour. In: PENNING, P.D. (Ed.). Herbage intake handbook. 2.ed. Reading: The British Grassland Society, 2004. p.151-175.

PINTO, C.E.; CARVALHO, C.F.C.; FRIZZO, A. et al. Comportamento ingestivo de novilhos em pastagem nativa no Rio Grande do Sul. Revista Brasileira de Zootecnia, v.36, n.2, p.319-327, 2007.

PORTUGAL, J.A.B.; PIRES, M.F.A.; DURÃES, M.C. Efeito da temperatura ambiente e da umidade relativa do ar sobre a frequência de ingestão de alimentos e de água e de ruminação em vacas de raça holandesa. Arquivo Brasileiro de Medicina Veterinária e Zootecnia, v.52, n.2, p.154-159, 2000.

ROOK, A.J. Principles of foraging and grazing behaviour. In: HOPKINS, A. (Ed.). Grass, its production and utilization. Oxford: Blackwell Science Ltda, 2000. p.229-246.

SALLA, L.E.; FISCHER, V.; FERREIRA, E.X. et al, Comportamento ingestivo de vacas Jersey alimentadas com dietas contendo diferentes fontes de gordura nos primeiros 100 dias de lactação. Revista Brasileira de Zootecnia, v.32, n.3, p.683-689, 2003.

SALLA, L.E.; MORENO, C.B.; FERREIRA, E.X. Avaliação do comportamento de vacas Jersey em lactação - Aspectos metodológicos I. In: REUNIÃO ANUAL DA SOCIEDADE BRASIlEIRA DE ZOOTECNIA, 36., 1999, Porto Alegre. Anais... Porto Alegre: Sociedade Brasileira de Zootecnia, 1999. (CD-ROM)

SILVA, R.R.; MAGAlHÃES, A.F.; CARVALHO, G.G.P. et al. Comportamento ingestivo de novilhas mestiças de holandês suplementadas em pastejo de Brachiaria. Aspectos metodológicos. Revista Eletrônica de Veterinária, v.5, n.10, p.1-10, 2004.

SILVA, R.R.; SILVA, F.F.; CARVALHO, G.G.P. et al. Avaliação do comportamento ingestivo de novilhas $3 / 4$ holandês x zebu alimentadas com silagem de capim-elefante acrescida de $10 \%$ de farelo de mandioca. Ciência Animal Brasileira, v.6, n.4, p.134-141, 2005

SILVA, R.R.; PRADO, I.N.; CARVALHO, G.G.P. et al. Efeito da utilização de três intervalos de observações sobre a precisão dos resultados obtidos no estudo do comportamento ingestivo de vacas leiteiras em pastejo. Ciência Animal Brasileira, v.9, n.2, p.319-326, 2008.

THUROW, J.M.; NABINGER, C.; CASTILHOS, Z.M.S. Estrutura da vegetação e comportamento ingestivo de novilhos em pastagem natural do Rio Grande do Sul. Revista Brasileira de Zootecnia, v.38, n.5, p.818-826, 2009. 